\title{
Histomorphologic superiority of internal thoracic arteries over right gastroepiploic arteries for coronary bypass
}

\author{
Tomohiro Nakajima, MD, Kazutoshi Tachibana, MD, Nobuyuki Takagi, MD, Toshiro Ito, MD, and \\ Nobuyoshi Kawaharada, MD
}

\begin{abstract}
Objective: In this study, we compared the histologic and morphometric properties of both internal thoracic arteries and the right gastroepiploic artery (GEA) in patients undergoing coronary artery bypass grafting (CABG).

Methods: We microscopically examined transverse sections of segments of both internal thoracic arteries and the right GEA obtained from 83 consecutive patients who underwent $\mathrm{CABG}$.

Results: There were no significant differences between the internal thoracic arteries. Significant differences were found between the left and right internal thoracic arteries and GEA in the intimal width $(21.8,21.5$, and $71.7 \mu \mathrm{m}$, respectively; $P<.01)$, intima-to-media ratio $(0.286,0.256$, and 0.749 , respectively; $P<.01)$, and media width $(148.5,157.5$, and $164.8 \mu \mathrm{m}$, respectively; $P=.43$ ). No atherosclerotic lesions, medial calcification, or intimal thickening were seen in the internal thoracic arteries; however, atherosclerotic lesions were seen in the GEA. The intima of the GEA was thicker than that of the internal thoracic arteries. Intimal thickening of the GEA, but not the internal thoracic arteries, was positively correlated with risk of arteriosclerosis. In patients with diabetes mellitus, dietary/drug therapy and insulin therapy were associated with GEA intimal thickness $(P=.02$ and .01 , respectively).
\end{abstract}

Conclusions: The internal thoracic arteries have equivalent histologic and morphometric properties that differ from those of the GEA only in intimal width. The former had no intimal thickening, and is thus preferable to the GEA for CABG. (J Thorac Cardiovasc Surg 2016;151:1704-8)

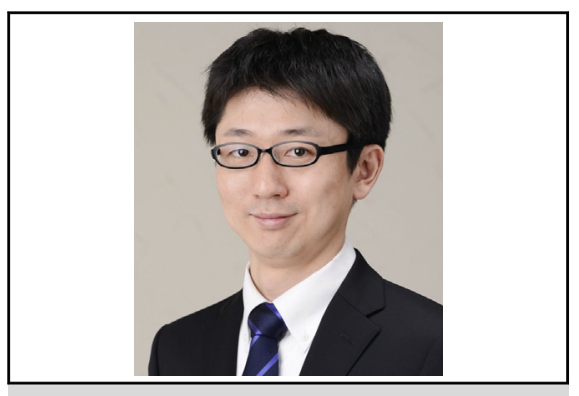

Tomohiro Nakajima, MD

\section{Central Message}

The intimal thickness of BITAs is not correlated with risk of arteriosclerosis; BITAs are thus preferable to the GEA for CABG.

\section{Perspective}

The present study indicates that the intimas of both internal thoracic arteries do not increase in thickness even in the presence of some risk factors for arteriosclerosis. However, the gastroepiploic artery intima readily thickens because it is easily affected by arteriosclerosis.

See Editorial Commentary page 1709.
Several strategies using arterial conduits have been employed to improve the long-term outcome after coronary artery bypass grafting (CABG). ${ }^{1}$ After Higami and colleagues $^{2}$ described procurement of the internal thoracic artery (ITA) using a Harmonic scalpel, it became possible to obtain sufficient vessel length for anastomosis to most coronary arteries for bypass grafting. Use of both ITAs (BITAs) for bypass grafts is currently favored. Thus,

From the Department of Cardiovascular Surgery, Sapporo Medical University School of Medicine, Sapporo, Japan.

Funding: This research did not receive any specific grant from any funding agency in the public, commercial or not-for-profit sector.

Received for publication Aug 21, 2015; revisions received Jan 15, 2016; accepted for publication Feb 4, 2016; available ahead of print March 11, 2016.

Address for reprints: Tomohiro Nakajima, MD, Department of Cardiovascular Surgery, Sapporo Medical University School of Medicine, South-1, West-16, Chuo-ku, Sapporo 060-8543, Japan (E-mail: t.nakajima@sapmed.ac.jp). 0022-5223/\$36.00

Copyright $₫ 2016$ Published by Elsevier Inc. on behalf of The American Association for Thoracic Surgery

http://dx.doi.org/10.1016/j.jtcvs.2016.02.018 identification of a third vessel suitable for CABG is needed. The great saphenous vein, right gastroepiploic artery (GEA), and radial artery have been considered as possibilities for the third vessel. ${ }^{4}$ Of these, the right GEA has been widely used and investigated as a suitable alternative arterial conduit. ${ }^{5}$ However, its small caliber and susceptibility to vasospasm are major drawbacks to its use. The skeletonization technique was initially used to procure the ITA. This technique reportedly increases its caliber, conduit length, and flow capacity. ${ }^{6,7}$ Gagliardotto and colleagues ${ }^{8}$ introduced the technique of skeletonized GEA procurement in 1998. Skeletonized GEAs can be expected to yield the same benefits as skeletonized ITAs and subsequently

Scanning this QR code will take you to the article title page.

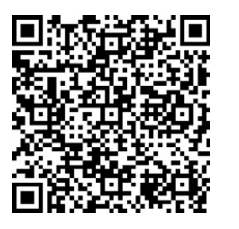



Abbreviations and Acronyms
BITAs $=$ both internal thoracic arteries
$\mathrm{CABG}=$ coronary artery bypass grafting
GEA $=$ gastroepiploic artery
$\mathrm{HbA1c}=$ glycated hemoglobin
ITA = internal thoracic artery
LITA $=$ left internal thoracic artery
RITA $=$ right internal thoracic artery

provide a better patency rate than pedicled GEAs. However, few studies have quantitatively evaluated skeletonized GEAs. ${ }^{9}$ The aim of our study was to examine the histologic and morphometric properties of BITAs and the GEA in the same patients undergoing CABG.

\section{METHODS}

During the 9 years from January 2006 to August 2014, CABG was performed in our hospital in 316 consecutive patients, in 128 of whom skeletonized GEAs and BITAs were used. The stumps of resected GEAs and BITAs of 83 of the patients who underwent coronary bypass surgery were assessed in this study. The segments obtained from the remaining 45 patients were excluded because they were distorted by surgical or pathologic preparation and consequently unsuitable for the morphometric analysis. In all, 79 segments from the left ITA (LITA), 73 from the right ITA (RITA), and 72 from the GEA were examined. The patients' baseline characteristics are summarized in Table 1. The glomerular filtration rate (calculated as $\mathrm{mL} / \mathrm{min} / 1.73 \mathrm{~m}^{2}$ ) was calculated from the Modification of Diet in Renal Disease equation. ${ }^{10}$

Our indication for the use of the GEA was $>75 \%$ stenosis of the right coronary territory. The GEAs were dissected distal to the midpoint of the greater curvature of the stomach and proximal to the pylorus. Full skeletonization of the whole length of BITAs and the GEA was performed with an ultrasonic scalpel. After systemic heparinization, the distal ends of the grafts were divided and $0.02 \%$ milrinone instilled into them, after which they were wrapped with $0.2 \%$ papaverine-soaked gauze. The required lengths of BITAs and the GEA were adjusted according to the target vessels and the redundant distal portions trimmed and sent to the laboratory. An off-pump technique was used in all patients. In our series, no GEAs were discarded on the basis of gross examination after opening the peritoneal cavity or having procured the graft.

Before the study, the patients gave written informed consent to the use of their medical records for research purposes. The institutional review board at our institution approved the study.

\section{Histopathologic Analysis}

Tissues obtained from BITAs and the GEA were fixed in 5.25\% formaldehyde, then embedded in paraffin wax, after which transverse sections (short-axis segments of the blood vessel) were cut. After dewaxing, the sections were stained with hematoxylin and eosin and Verhoeff-van Gieson. For morphometric analysis, the following variables were measured using a medical imaging system (Osirix MD; Pixmeo, Geneva, Switzerland): maximum intimal width, media width at maximal intimal thickness, and wall thickness. Intimal thickening was also evaluated using the ratio of the maximal intimal width to the media width at maximal intimal thickness. Intimal hyperplasia was defined as $>30 \mu \mathrm{m}^{11,12}$ The maximum intimal width, media width at maximal intimal thickness, and wall thickness were assessed by dividing the section into 8 equal sectors of $45^{\circ}$. Atherosclerotic lesions were defined by the presence of intimal lipids lying free as cholesterol clefts or in aggregates of foamy
TABLE 1. Baseline characteristics of study patients $(N=83)$

\begin{tabular}{lc}
\hline \multicolumn{1}{c}{ Characteristic } & Result \\
\hline Age (y) & $69.7 \pm 8.5$ \\
Female sex & $18(21.7)$ \\
Body mass index & $23.8 \pm 3.3$ \\
Smoking & $43(51.8)$ \\
Diabetes & $34(40.9)$ \\
Glycated hemoglobin (\%) & $5.98 \pm 1.14$ \\
Diet control & $5(6.0)$ \\
Oral hypoglycemic drugs & $20(24.1)$ \\
Insulin injection & $9(10.8)$ \\
Estimated glomerular filtration rate & \\
$\quad>60$ & $56(67.5)$ \\
$30-60$ & $23(27.7)$ \\
$\quad<30$ & $4(4.8)$ \\
Chronic hemodialysis & $1(1.2)$ \\
Hypertension & $67(80.2)$ \\
Peripheral arterial disease & $9(10.8)$ \\
Hyperlipidemia & $60(72.3)$ \\
\hline
\end{tabular}

Values are presented as mean \pm standard deviation or $\mathrm{n}(\%)$.

macrophages. Medial calcification was considered present when calcium crystals were observed in the tunica media (Figure 1).

\section{Statistical Analysis}

The association between preoperative risk factors and intimal hyperplasia was assessed by stepwise linear regression analysis. The following 10 clinical risk factors were included as independent variables: age, sex, body mass index, smoking, diabetes, glycated hemoglobin (HbA1c) concentration, estimated glomerular filtration rate, hypertension, peripheral arterial disease, and hyperlipidemia. Correlations between 2 continuous variables were checked using the Spearman rank correlation test. Continuous data are expressed as mean \pm standard deviation and categorical data as number and percent. Univariate analysis for risk factors associated with intimal hyperplasia was performed using the Cox regression test. All variables with $P$ values $<.10$ were included in a

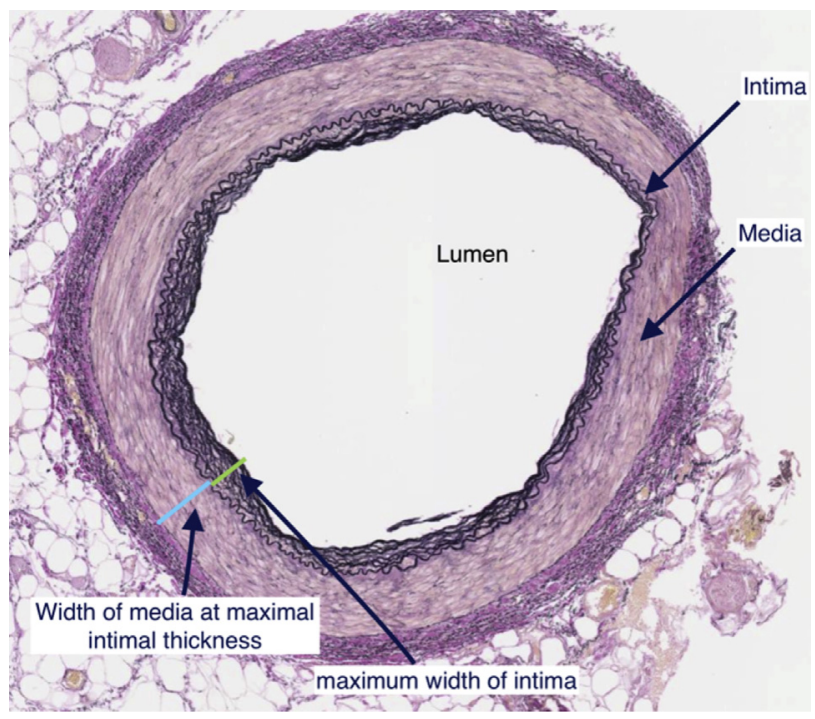

FIGURE 1. Representative gastroepiploic artery section showing indices used to evaluate severity of intimal thickness (Elastica van Gieson stain; original magnification, $\times 20$ ). 
TABLE 2. Morphometric variables in both internal thoracic arteries (ITAs) and gastroepiploic artery (GEA) segments

\begin{tabular}{|c|c|c|c|c|}
\hline & $\begin{array}{c}\text { Left ITA } \\
(n=79)\end{array}$ & $\begin{array}{c}\text { Right ITA } \\
(n=73)\end{array}$ & $\begin{array}{c}\text { GEA } \\
(n=72)\end{array}$ & $P$ value \\
\hline Width of intima $(\mu \mathrm{m})$ & $21.8 \pm 12.5$ & $21.5 \pm 11.1$ & $71.7 \pm 45.8$ & $<.01$ \\
\hline Width of media $(\mu \mathrm{m})$ & $148.5 \pm 47.2$ & $157.5 \pm 41.7$ & $164.8 \pm 56.0$ & .34 \\
\hline Lumen area $\left(\mathrm{mm}^{2}\right)$ & $0.752 \pm 0.404$ & $0.903 \pm 0.462$ & $0.928 \pm 0.501$ & .28 \\
\hline Intimal area $\left(\mathrm{mm}^{2}\right)$ & $0.102 \pm 0.073$ & $0.107 \pm 0.071$ & $0.289 \pm 0.237$ & $<.01$ \\
\hline Maximum width of intima $(\mu \mathrm{m})$ & $37.3 \pm 25.6$ & $39.1 \pm 30.6$ & $109.4 \pm 65.4$ & $<.01$ \\
\hline Width of media at maximal intimal thickness $(\mu \mathrm{m})$ & $145.4 \pm 47.2$ & $162.1 \pm 41.7$ & $162.9 \pm 66.2$ & .68 \\
\hline Intima-to-media ratio & $0.286 \pm 0.214$ & $0.256 \pm 0.222$ & $0.749 \pm 0.448$ & $<.01$ \\
\hline
\end{tabular}

Values are presented as mean \pm standard deviation.

multivariate Cox regression analysis. All statistical testing was 2-sided. All analyses were performed with the SPSS statistical package version 22.0 (IBM-SPSS Inc, Armonk, NY).

\section{RESULTS}

Intimal hyperplasia was seen in $129(57.6 \%)$ of 224 segments: 33 from the LITA, 34 from the RITA, and 62 from the GEA. Seven patients had intimal hyperplasia in paired segments obtained from both BITAs and 33 in segments obtained from a single ITA. No atherosclerotic lesions or medial calcification were seen in the ITAs. In contrast, atherosclerotic lesions, including moderate concentric atheromatous intimal thickening involving the whole circumference, were seen in 9 segments $(8.3 \%)$ from the GEA; however, no medial calcification was observed.

The results of morphometric analysis are summarized in Table 2. Although no histologic differences between the LITAs and RITAs were observed, there were significant differences in intimal width, intimal area, maximum intimal width, and intima-media ratio between BITAs and the GEA. No significant differences were found in width or area of the media between the RITA, LITA, and GEA. Thus, there was no difference between the LITAs and RITAs. The GEA intima was thicker than the ITA intima.

Figure 2 shows GEA specimens from 2 different patients with very different intimal widths. Figure 3 shows GEA,
LITA, and RITA specimens from the same patient. The intimal width did not differ significantly between the LITA and RITA in this patient. In contrast, there was only a slight difference in the width of the ITA intima.

Table 3 summarizes the results of comparing baseline characteristics between patients with and without GEA intimal hyperplasia. A greater percentage of patients with than without intimal hyperplasia were receiving diet therapy, oral hypoglycemic drug therapy, or insulin injections for diabetes mellitus. No significant differences were found in sex, smoking history, hypertension, or hyperlipidemia. The thickness of the GEA intima differed depending on some patient characteristics; specifically, it increased in parallel with $\mathrm{HbAlc}$ concentrations, whereas the intima of BITA did not (Figure 4). Correlations between continuous variables were checked using the Spearman rank correlation test.

\section{DISCUSSION}

Our study has 2 important findings. First, the skeletonized BITAs exhibited no laterality and had adequate lumens. Furthermore, there were few differences in thickness between the LITAs and RITAs and their intimal thickness was not correlated with risk of arteriosclerosis. Considering a report that intimal thickening is a risk factor for occlusion after CABG, ${ }^{13}$ less thickening of BITAs is
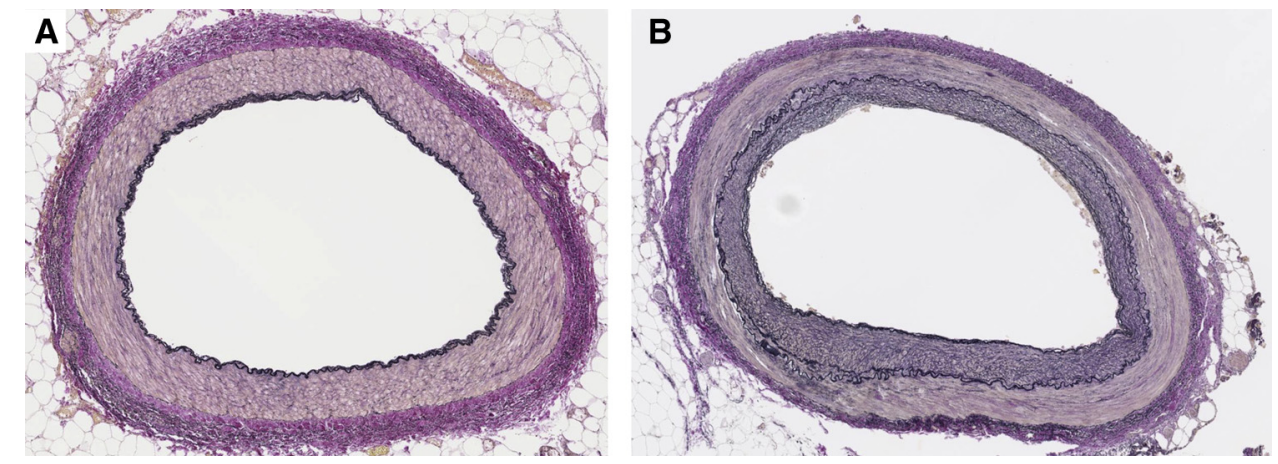

FIGURE 2. Gastroepiploic artery (GEA) specimens from 2 different patients. A, GEA with concentric nonatheromatous intimal thickening (Elastica van Gieson stain; original magnification, $\times 40)$. This patient was a 52-year-old man with hypertension and hyperlipidemia; his glycated hemoglobin $(H b A 1 c)$ concentration was $5.4 \%$. B, Normal GEA. The intima is a very thin layer consisting mainly of endothelium (Elastica van Gieson stain; original magnification, $\times 40$ ). This patient was a 70-year-old woman with diabetes, smoking, hypertension, and hyperlipidemia; her HbA1c was $6.6 \%$. 

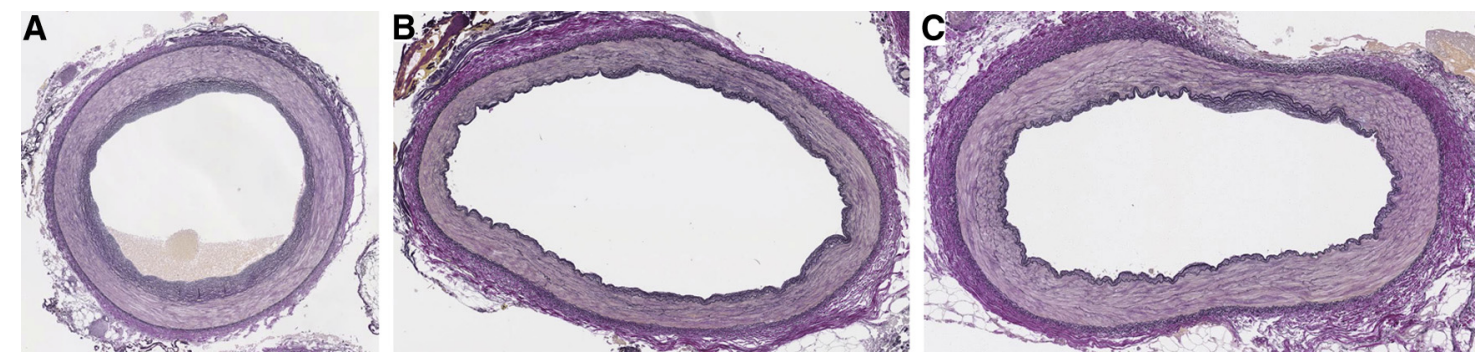

FIGURE 3. Three histopathologic specimens from 1 patient. This patient was a 60 -year-old man with hypertension and hyperlipidemia; his glycated hemoglobin $(H b A l c)$ was $6.0 \%$. A, Gastroepiploic artery $(G E A)$ with moderate concentric nonatheromatous intimal thickening. B, Normal left internal thoracic artery (LITA). The intima is a very thin layer consisting mainly of endothelium resting on the internal elastic lamina. C, Normal right internal thoracic artery (RITA). The intima is very thin (Elastica van Gieson stain; original magnification, $\times 40$ ).

likely associated with long-term patency. The intimal thickness of BITAs did not differ significantly between the patients in this study, reconfirming the use of the ITA as the gold standard for CABG and indicating that the use of BITAs is desirable. ${ }^{3}$ However, some studies have reported that the use of the BITAs increases the risk of infections such as mediastinitis; therefore, careful judgment regarding their application is required. ${ }^{14,15}$

Second, the intima of the GEA was thicker than that of BITAs. No significant difference was found between the BITAs and GEA in the area of the lumen or thickness of the media. The degree of intimal thickening in the GEA differed among the patients. Patients with diabetes mellitus were more likely to exhibit intimal thickening of the GEA. Our findings are in agreement with previous findings of the lack of an association between age and renal function and GEA intimal thickening. There are reports that the radial artery intima is thicker than the ITA intima, and its long-term prognosis for CABG is poor. ${ }^{16,17}$ Likewise, our finding that the intima of the GEA is thicker than that of BITAs supports previous findings of poor long-term patency of the GEA. ${ }^{18}$ The intima of the saphenous vein

TABLE 3. Risk factors for atherosclerosis by presence or absence of intimal hyperplasia in the gastroepiploic artery $($ GEA) $(n=72)$

\begin{tabular}{lccc}
\hline & $\begin{array}{c}\text { GEA with } \\
\text { intimal } \\
\text { hyperplasia } \\
(\mathbf{n}=\mathbf{6 2})\end{array}$ & $\begin{array}{c}\text { GEA without } \\
\text { intimal } \\
\text { hyperplasia } \\
(\mathbf{n}=\mathbf{1 0})\end{array}$ & $\begin{array}{c}\boldsymbol{P} \\
\text { value }\end{array}$ \\
\hline Age $>60$ y & $60(96.8)$ & $3(30.0)$ & .50 \\
Male & $53(85.5)$ & $8(80.0)$ & .77 \\
Smoking & $38(61.3)$ & $5(50.0)$ & .61 \\
Diabetes & & & \\
$\quad$ Diet control or drugs & $25(40.3)$ & 0 & .02 \\
$\quad$ Insulin injection & $5(8.1)$ & $4(40.0)$ & .01 \\
Estimated glomerular & $3(4.8)$ & $1(10.0)$ & .71 \\
$\quad$ filtration rate $<30$ & & & \\
Hypertension & $59(95.2)$ & $9(90.0)$ & .48 \\
Hyperlipidemia & $51(82.3)$ & $7(70.0)$ & .31 \\
\hline
\end{tabular}

Values are presented as $\mathrm{n}(\%)$. is also thicker than that of BITAs. ${ }^{19}$ For this reason, saphenous vein grafts do not exhibit good long-term patency. ${ }^{20,21}$

Patients who undergo CABG often have several risk factors for arteriosclerosis. This condition does not spare the distal arteries. Our study results indicate that the intima of BITAs does not increase in thickness even in the presence of some risk factors for arteriosclerosis. In contrast, the GEA intima readily thickens because it is easily affected by arteriosclerosis. However, given our patients' backgrounds, we consider that arteries distal to the GEA are likely affected by arteriosclerosis, whereas the BITAs may not be affected. Reddy and colleagues ${ }^{21}$ reported that the width of the intima of the LITA and RITA is equal in patients without coronary artery disease; this is also true of patients with coronary artery disease. The degree of intimal thickening at the time of procurement is likely to contribute to long-term patency for CABG, as are other clinical factors such as the graft type, stenosis of the native coronary arteries, and graft blood flow velocities. ${ }^{22}$ In our

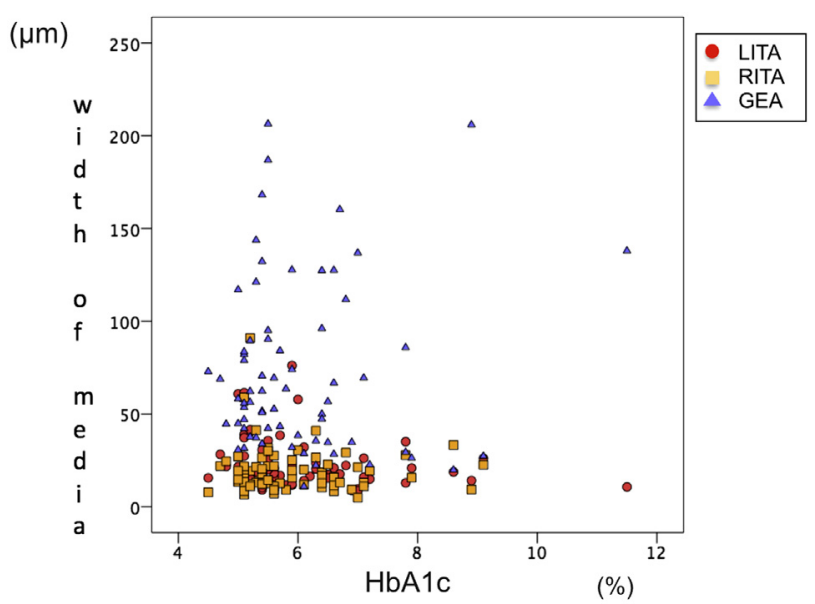

FIGURE 4. Scatter plot of intimal width of the left internal thoracic artery (LITA), right internal thoracic artery (RITA), and gastroepiploic artery (GEA). The GEA is variously scattered, and the intimal thickness increases in parallel with the glycated hemoglobin $(H b A l c)$ concentration, whereas the intima of both internal thoracic arteries does not. 
study, the GEA intima was more likely to be thick in patients with diabetes.

This study has several limitations. First, the number of patients was small, and there was no comparison group. Second, the vessels analyzed in the study were discarded distal graft segments. Depending on the patients, some arteries were procured from distal areas, whereas others were procured more proximally; thus, arteries procured from different areas were evaluated in this study. Finally, the lack of available coronary angiography hindered evaluation of the association between our microscopic findings and long-term graft patency.

\section{CONCLUSIONS}

The RITAs and LITAs exhibited no histologic differences and no intimal thickening in our study. The intima of the BITAs was not thick even in patients with many coronary risk factors. We have thus demonstrated that BITAs are histologically suitable grafts for CABG. In contrast, although the skeletonized GEAs had sufficiently wide lumens, they exhibited moderate concentric atheromatous intimal thickening involving the whole circumference. Diabetes mellitus is significantly correlated with intimal hyperplasia of the GEA. HbA1c concentrations are related to GEA intimal thickness.

\section{Conflict of Interest Statement}

Authors have nothing to disclose with regard to commercial support.

\section{References}

1. Kinoshita T, Asai T, Nishimura O, Suzuki T, Kambara A, Matsubayashi K. Off-pump bilateral versus single skeletonized internal thoracic artery grafting in patients with diabetes. Ann Thorac Surg. 2010;90:1173-9.

2. Higami T, Kozawa S, Asada T, Shida T, Ogawa K. Skeletonization and harvest of the internal thoracic artery with an ultrasonic scalpel. Ann Thorac Surg. 2000;70: 307-8.

3. Nicolini F, Agostinelli A, Spaggiari I, Vezzani A, Benassi F, Maestri F, et al. Current trends in surgical revascularization of multivessel coronary artery disease with arterial grafts. Int Heart J. 2014;55:381-5.

4. Glineur D. Importance of the third arterial graft in multiple arterial grafting strategies. Ann Cardiothorac Surg. 2013;2:475-80.

5. Suzuki T, Asai T, Matsubayashi K, Kambara A, Kinoshita T, Takashima N, et al. In off-pump surgery, skeletonized gastroepiploic artery is superior to saphenous vein in patients with bilateral internal thoracic arterial grafts. Ann Thorac Surg. 2011;91:1159-64.
6. Wendler O, Tscholl D, Huang Q, Schafers HJ. Free flow capacity of skeletonized versus pedicled internal thoracic artery grafts in coronary artery bypass grafts. Eur J Cardiothorac Surg. 1999;15:247-50.

7. Calafiore AM, Vitolla G, Iaco AL, Fino C, Di Giammarco G, Marchesani F, et al. Bilateral internal mammary artery grafting: midterm results of pedicled versus skeletonized conduits. Ann Thorac Surg. 1999;67:1637-42.

8. Gagliardotto P, Coste P, Lazreg M, Dor V. Skeletonized right gastroepiploic artery used for coronary artery bypass grafting. Ann Thorac Surg. 1998;66:240-2.

9. Phung DV, Kinoshita T, Asai T, Suzuki T. Histological and morphometric properties of skeletonized gastroepiploic artery and risk factors for intimal hyperplasia. Innovations. 2012;7:191-4.

10. Valente MA, Hillege HL, Navis G, Voors AA, Dunselman PH, van Veldhuisen DJ, et al. The Chronic Kidney Disease Epidemiology Collaboration equation outperforms the Modification of Diet in Renal Disease equation for estimating glomerular filtration rate in chronic systolic heart failure. Eur J Heart Fail. 2014;16:86-94.

11. Otsuka F, Yahagi K, Sakakura K, Virmani R. Why is the mammary artery so special and what protects it from atherosclerosis? Ann Cardiothorac Surg. 2013;2:519-26.

12. Ojha M, Leask RL, Johnston KW, David TE, Butany J. Histology and morphology of 59 internal thoracic artery grafts and their distal anastomoses. Ann Thorac Surg. 2000;70:1338-44.

13. Kinoshita T, Asai T, Suzuki T, Phung DV. Histomorphology of right versus left internal thoracic artery and risk factors for intimal hyperplasia. Eur $J$ Cardiothorac Surg. 2014;45:726-31.

14. Hu X, Zhao Q. Skeletonized internal thoracic artery harvest improves prognosis in high-risk population after coronary artery bypass surgery for good quality grafts. Ann Thorac Surg. 2011;92:48-58.

15. Deo SV, Shah IK, Dunlay SM, Erwin PJ, Locker C, Altarabsheh SE, et al. Bilateral internal thoracic artery harvest and deep sternal wound infection in diabetic patients. Ann Thorac Surg. 2013;95:862-9.

16. Ruengsakulrach P, Sinclair R, Komeda M, Raman J, Gordon I, Buxton B Comparative histopathology of radial artery versus internal thoracic artery and risk factors for development of intimal hyperplasia and atherosclerosis. Circulation. 1999;100:139-44.

17. Schwann TA, Al-Shaar L, Engoren M, Habib RH. Late effects of radial artery vs saphenous vein grafting for multivessel coronary bypass surgery in diabetics: a propensity-matched analysis. Eur J Cardiothorac Surg. 2013;44:701-10.

18. Suma H, Tanabe H, Yamada J, Mikuriya A, Horii T, Isomura T. Midterm results for use of the skeletonized gastroepiploic artery graft in coronary artery bypass. Circ J. 2007;71:1503-5.

19. Une D, Kulik A, Voisine P, Le May M, Ruel M. Correlates of saphenous vein graft hyperplasia and occlusion 1 year after coronary artery bypass grafting analysis from the CASCADE randomized trial. Circulation. 2013;128(Suppl): S213-8.

20. Harskamp RE, Williams JB, Hill RC, de Winter RJ, Alexander JH, Lopes RD, et al. Saphenous vein graft failure and clinical outcomes: Toward a surrogate end point in patients following coronary artery bypass surgery? Am Heart J. 2013;165:639-43.

21. Reddy S, Kumar P, Prasad K. Histomorphometric and sympathetic innervation of the human internal thoracic artery. Clinics (Sao Paolo). 2011;66:131-6.

22. Barner HB. Remodeling of arterial conduits in coronary grafting. Ann Thorac Surg. 2002;73:1341-5.

Key Words: internal thoracic artery, gastroepiploic artery, coronary artery bypass grafting, intimal hyperplasia 